\title{
Uneventful Recovery from a Suicide Attempt with Tetrabenazine: A Case Report
}

\author{
Tetrabenazinle İntihar Girişimi Sonrası Sorunsuz İyileşme: Olgu Sunumu
}

Ece Bayram, Fatma Nazlı Durmaz, Muhittin Cenk Akbostanc1

Ankara University Faculty of Medicine, Department of Neurology, Ankara, Turkey

\section{Summary}

Patients with Huntington's disease (HD) have involuntary choreiform movements, dementia, psychiatric disorders and behavioral abnormalities. Suicide is very frequent with this disease and is the third most common cause of death. Depression is one of the common adverse effects of tetrabenazine, a drug used to treat chorea in HD, and this may increase the suicide rate in this disease. We report a patient who attempted suicide by taking tetrabenazine and recovered after treatment.

Keywords: Huntington's disease, tetrabenazine, suicide

\section{$\ddot{\mathbf{O} z}$}

Huntington hastalı̆̆ı $(\mathrm{HH})$ olan hastalarda istemsiz koreiform hareketler, demans, psikiyatrik bozukluklar ve davranışsal anormallik şikayetleri görülür. İntihar meyli, hastalıkta oldukça sık görülür ve bu hastalardaki üçüncü en sık görülen ölüm sebebidir. Tetrabenazin, HH'de görülen korenin tedavisi için kullanılan bir ilaçtır ve sık yan etkilerinden birinin depresyon olması nedeniyle hastalarda intihar riski yükselebilir. Bu, tetrabenazin alarak intihara kalkışmış ve tedavi sonrası iyileşmiş bir hastanın olgu sunumudur.

Anahtar Kelimeler: Huntington hastalı̆̆ı, tetrabenazin, intihar

\section{Introduction}

Huntington's disease (HD) is an autosomal dominant disorder characterized by involuntary choreiform movements, cognitive decline, psychiatric disorders, and behavioral abnormalities. The behavioral and psychiatric problems have been shown to disturb patients and their relatives more than chorea (1). George Huntington highlighted that the increased risk of suicide is an important part of HD (2).

There is no cure for HD at the moment; however symptomatic treatment can be provided. Tetrabenazine, which was approved by the United States Food and Drug Administration in 2008 for the treatment of Huntington's chorea, depletes presynaptic dopamine by inhibition of vesicular monoamine transporter 2 (VMAT2). Tetrabenazine is the first-choice drug to symptomatically treat chorea in HD (3).

Suicide is the third most common cause of death in HD (4). Whether tetrabenazine increases the suicide risk has yet to be established. Nevertheless, physicians should pay attention to the adverse effects of tetrabenazine, which lead to an increased risk of suicide. This is a case report of a patient with HD who attempted suicide by taking an overdose of her tetrabenazine medication. This case is presented to discuss the increased suicide risk effect as well as acute effects of high-dose tetrabenazine. To our knowledge, this is the third case of self-poisoning with tetrabenazine.

\section{Case Report}

A woman aged 54 year years with a 10-year history of HD was admitted to the emergency service with symptoms of drowsiness, dizziness, nausea, vomiting, and difficulty in movement.

During the neurologic examination, the patient opened her eyes in response to verbal commands; however, she did not reply to questions and followed only one step motor commands. She had hypomimia and bilateral symmetrical bradykinesia and 
rigidity. Her medical history showed that she had been taking tetrabenazine 75 milligrams/day for the past 3 months and sertraline 50 milligrams/day for the past 2 months. She had previously been diagnosed as having HD and an anxiety disorder. She had no previous suicide attempts.

The patient's daughter informed us that 32 tablets of tetrabenazine (in total 625 milligrams of tetrabenazine) were missing from the box. The patient also stated that she had taken them to commit suicide an hour before she was brought to the hospital. Blood level of tetrabenazine was not checked; however, the patient's daughter and the patient's claims in addition to the development of drowsiness and parkinsonism supported selfpoisoning with tetrabenazine. Lack of prolonged QT interval in electrocardiogram (ECG), no increase in creatine phosphokinase $(\mathrm{CPK})$, and monitoring consciousness eliminated the possibility of neuroleptic malignant syndrome caused by tetrabenazine.

The patient was hydrated and detoxicated with active charcoal. Renal and hepatic dysfunction, and respiratory problems were not present. She was hospitalized and fully recovered with resolution of parkinsonism in 48 hours. In the long term; tetrabenazine 75 milligrams/day was continued, sertraline was increased to 100 milligrams/day and 15 milligrams/day of clonazepam was added to her medication.

\section{Discussion}

Suicide is an avoidable cause of death in HD. Physicians should be careful about depression and suicidal ideation in patients, because they are very common in HD. Studies have shown that suicide risk for patients with HD is four to eight times higher than the general population $(4,5,6)$.

Tetrabenazine, a drug used to treat symptomatic Huntington's chorea, is a very effective drug with relatively low-risk adverse effects. Shen et al. (7) reported that they had to discontinue tetrabenazine in 2 out of 145 patients because of suicidal ideation, which resolved after treatment cessation. The Huntington's Study Group reported a patient in their tetrabenazine group who committed suicide (8). Other studies have indicated that tetrabenazine is not associated with suicide (9). Dorsey et al. (10) reported that in 1360 patients with HD who were taking tetrabenazine, they found no association of tetrabenazine with increased risk of suicidal ideation, suicide attempts, suicide or depressed mood.

Self-poisoning with tetrabenazine is rarely reported. A woman aged 27 years was reported to have experienced sedation only, with no significant sequelae, after ingestion of 1 gram of tetrabenazine (11). Also in an efficacy study, one out of 31 patients using tetrabenazine discontinued therapy because of self-poisoning (12). The most common acute adverse effects are reversible when the dose is decreased and include drowsiness/sedation, weakness, parkinsonism, depression, and acute akathisia $(9,13)$. Other much rarer adverse effects include insomnia, nervousness/anxiety, nausea and vomiting, tremor, memory problems, confusion, "trance-like/zombie," orthostatic hypotension, balance and gait difficulties, dizziness, diarrhea, headaches, hallucinations, paresthesias, pharyngeal spasm and pain, blurred vision, panic attacks, and paranoia (13). There are no reports of significant persistent long-term changes (13).
An important limitation of this case report is the inability to report the blood level of tetrabenazine. It may have been helpful to discuss the amount of tetrabenazine in the blood that lead to the reported clinical conditions. Future studies may benefit from assessing the adverse effects for different doses of tetrabenazine.

Patients with HD benefit from tetrabenazine regarding the symptomatic treatment of their chorea. Fortunately, depression caused by tetrabenazine is reported to be responsive to antidepressants (14). However, physicians should be alert to its adverse effects, which include depression and increased suicide risk, and instead of stopping tetrabenazine, concomitant antidepressant use should be considered if necessary.

\section{Authorship Contributions}

Informed Consent: Consent form was filled out by the participant, Concept: Ece Bayram, Fatma Nazli Durmaz, Mubittin Cenk Akbostancı, Design: Ece Bayram, Fatma Nazlı Durmaz, Mubittin Cenk Akbostanci, Data Collection or Processing: Ece Bayram, Fatma Nazlı Durmaz, Mubittin Cenk Akbostancı, Analysis or Interpretation: Ece Bayram, Fatma Nazli Durmaz, Literature Search: Ece Bayram, Fatma Nazln Durmaz, Writing: Ece Bayram, Fatma Nazlı Durmaz, Mubittin Cenk Akbostancı, Peer-review: Externally peer-reviewed. Conflict of Interest: The authors declare no conflict of interest, Financial Disclosure: The authors declare that this study has received no financial support.

\section{References}

1. Hamilton JM, Salmon DP, Corey-Bloom J, Gamst A, Paulsen JS, Jerkins S, Jacobson MW, Peavy G. Behavioural abnormalities contribute to functional decline in Huntington's disease. J Neurol Neurosurg Psychiatry 2003;74:120122.

2. Huntington G. On chorea. Med Surg Rep 1872;26:317-321.

3. McLellan DL, Chalmers RJ, Johnson RH. A double-blind trial of tetrabenazine, thiopropazate and placebo in patients with chorea. Lancet 1974;26:104-107.

4. Schoenfeld M, Myers RH, Cupples LA, Berkman B, Sax DS, Clark E. Increased rate of suicide among patients with Huntington's disease. J Neurol Neurosurg Psychiatry 1984; $47: 1283-1287$.

5. Farrer LA. Suicide and attempted suicide in Huntington disease: implications for preclinical testing of persons at risk. Am J Med Genet 1986;24:305-311.

6. Robins Wahlin TB, Backman L, Lundin A, Haegermark A, Winblad B, Anvret M. High suicidal ideation in persons testing for Huntington's disease. Acta Neurol Scand 2000;102:150-161.

7. Shen V, Clarence-Smith K, Hunter C, Jankovic J. Safety and efficacy of tetrabenazine and use of concomitant medications during long-term, openlabel treatment of chorea associated with Huntington's and other diseases. Tremor Other Hyperkinet Mov (NY) 2013:3.

8. Huntington Study Group. Tetrabenazine as antichorea therapy in Huntington disease: a randomized controlled trial. Neurology 2006;66:366-372.

9. Paleacu D. Tetrabenazine in the treatment of Huntington's disease. Neuropsychiatr Dis Treat 2007;3:545-551.

10. Dorsey ER, Brocht AF, Nichols PE, Darwin KC, Anderson KE, Beck CA, Singh S, Biglan KM, Shoulson I. Depressed mood and suicidality in individuals exposed to tetrabenazine in a large Huntington disease observational study. J Huntingtons Dis 2013;2:509-515.

11. Kidd DW, McLellan DL. Self-poisoning with tetrabenazine. Br J Clin Pract 1972;26:179-180.

12. Yero T, Rey JA. Tetrabenazine (Xenazine), An FDA-approved treatment option for Huntington's disease-related chorea. PT 2008;33:690-694.

13. Jankovic J, Beach J. Long-term effects of tetrabenazine in hyperkinetic movement disorders. Neurology 1997;48:358-362.

14. Soutar CA. Tetrabenazine for Huntington's chorea. Br Med J 1970;4:55. 